\title{
DO RITUAL AO GLOBAL: espetacularização das culturas e religiões populares
}

\author{
Del ritual al global: espectácularización de las culturas y religiones \\ populares \\ FROM RITUAL TO GLOBAL: “spectacularization” of cultures and \\ popular religions
}

\begin{abstract}
Ana Paula Santos Horta ${ }^{1}$
\section{Resumo}

Do ritual ao global: espetacularização das culturas e religiões populares, além de ser o título deste artigo é o tema da tese de doutorado que está sendo desenvolvida na UNESP, na área Ciências Sociais sob a orientação do Prof. Dr. Edmundo Peggion. A pesquisa em desenvolvimento faz uma análise teórica e empírica de algumas festas religiosas e populares brasileiras, investigadas a partir da etnografia do professor, educador popular, cientista social, ativista, escritor e antropólogo Carlos Rodrigues Brandão. A abordagem metodológica de base antropológica privilegia as dimensões teórica e documental abrangendo também uma pesquisa de campo, a partir de observação participante. O objetivo do trabalho é discutir o processo de mundialização/globalização da cultura e identificar elementos de ressignificação, transformação e espetacularização de rituais religiosos. Este artigo apresenta uma visão geral da investigação em andamento e algumas considerações parciais sobre o assunto.
\end{abstract}

Palavras-Chave: espetacularização; festas populares; globalização; rituais.

\section{Resumen}

Del ritual al global: espectacularización de las culturas y religiones populares, además de ser el título de este artículo, es el tema de la tesis de doctorado que estoy desarrollando en la UNESP, en el área Ciencias Sociales bajo la orientación del Prof. Dr. Edmundo Peggion. La investigación en desarrollo hace un análisis teórico y empírico de algunas fiestas religiosas y populares brasileñas, investigadas a partir de la etnografía del profesor, educador popular, científico social, activista, escritor y antropólogo Carlos Rodrigues Brandão. El enfoque metodológico de base antropológica privilegia las dimensiones teórica y documental abarcando también una investigación de campo, a partir de observación participante. El objetivo del trabajo es discutir el proceso de mundialización/globalización de la cultura e identificar elementos de resignificación, transformación y espectacularización de rituales religiosos. Este artículo presenta una visión general de la investigación en curso y algunas consideraciones parciales sobre el tema.

Palabras claves: espectacularización; fiestas populares; globalización; rituales.

\section{Abstract}

From ritual to global: exhibitionism of popular cultures and religions, is the title of this article and the theme of the doctoral thesis that I am developing at UNESP, in the Social Sciences discipline under the guidance of Prof. Dr. Edmundo Peggion. The research in development makes a theoretical and empirical analysis of some

${ }^{1}$ (Doutoranda em Ciências Sociais pelo PPGCSO da Universidade Estadual Paulista Júlio de Mesquita Filho (UNESP); docente na Libertas Faculdades Integradas; São Sebastião do Paraíso, Minas Gerais, Brasil; nirvana.horta@gmail.com). Trabalho apresentado no I Seminário Latino-Americano de Estudos em Cultura SEMLACult, Foz do Iguaçu/PR, Brasil, 2017. 
religious and popular Brazilian festivals, investigated from the ethnography of the professor's stance as a popular educator, social scientist, activist, writer and anthropologist Carlos Rodrigues Brandão. The methodological approach based on anthropology privileges the theoretical and documentary dimensions also encompassing a field research, based on participant observation. The objective of this work is to discuss the process of worldwide globalization of culture and to identify elements of re-signification, transformation of religious rituals into spectacle (Middle English: via Old French from Latin spectaculum 'public show.') This article presents an overview of ongoing research and some partial considerations on the subject.

Keywords: globalization; popular celebrations; rituals; spectacularization.

\section{Introdução}

No esteio da etnografia clássica relativa às festas populares no Brasil, esse texto tenta alinhar o debate sobre cultura popular com a problemática da modernidade e dos processos de modernização, tendo sempre em vista a superação das operações analíticas que substanciam o popular, como um tipo de alteridade ideal e autêntica, em oposição dicotômica à chamada indústria cultural.

Vale lembrar que "o entretenimento popular tem suas raízes no espetáculo, uma vez que a guerra, a religião, os esportes e outros domínios da vida pública foram terrenos férteis para a propagação do espetáculo por séculos”. (KELLNER, 2007, p.120). Nos dias atuais, com o desenvolvimento de novas tecnologias de informação e das novas formas de apropriação pelo mercado das ditas culturas populares, o espetáculo é midiático e se estende de forma polissêmica nos campos da economia, política, sociedade, cultura e do cotidiano, sendo, portanto, plural à medida que se revela vários níveis de espetáculos. As "festasespetáculo", de acordo com Edson Farias (2011), estão diretamente conectadas às transformações estruturais da sociedade-nação, essa última cada vez mais ordenada pela autorregulação do mercado e pelo comércio.

A espetacularização das festas populares brasileiras, assim como a desagregação familiar, o êxodo rural, o consumismo, o turismo já eram observados pelo antropólogo Carlos Rodrigues Brandão (CRB), ainda que de forma incipiente no decorrer de 1970 e 1980, como consequência da globalização. Estas características, ainda em potencial, estavam expressas na opinião dos agentes da Festa que declaravam: "a Festa do Divino não é a mesma" [informação oral]. As festas pesquisadas por CRB em Pirenópolis (Brandão, 1974) e na cidade de Goiás (Brandão, 2009a) se transformaram em verdadeiros espetáculos de massa aliados ao consumo e ao turismo, todavia não é exagero dizer que a espetacularização das culturas populares não é algo tão novo quanto se pensa. Assim, entendemos que a mudança 
está nos métodos de produção, na velocidade da divulgação e no mercado de consumo desses bens culturais.

Com Ortiz (2007) ressaltamos a importância de considerar o processo de mundialização como um fenômeno social total que permeia o conjunto das manifestações culturais, sem perder de vista as consequências da modernização e o surgimento de diversos mercados e novos negócios globais que lidam com o simbólico. Nesse sentido, ressaltamos que as implicações da mundialização redefinem hoje o que é cultura popular e nos faz pensar para além da sua produção, na circulação e no consumo de bens simbólicos e materiais a ela atrelados. Afinal, o estudo da cultura enquanto produção supõe, de acordo com Nestor Canclini (1983), considerar não apenas o ato de produzir, mas todas as etapas do processo produtivo: a produção, a circulação e a recepção.

Trata-se de outro modo de dizer que a análise de uma cultura não pode concentrar-se nos objetos ou nos bens culturais, deve ocupar-se do processo de produção e circulação social dos objetos e dos significados que receptores diferentes lhes atribuem. Uma dança de mouros e cristãos apresentada no interior de uma comunidade indígena por eles e para eles não é a mesma dança quando apresentada num teatro urbano para um público que é alheio a essa tradição, embora as suas estruturas formais sejam idênticas. Somente uma visão global do processo pode explicar o sentido desta produção deslocada na sua trajetória social (CANCLINI, 1983, p. 33)

Estudar cultura popular nos dias atuais, indagando-se, entre outras questões, como o consumo urbano altera o significado da produção material e simbólica das culturas tradicionais, requer uma estratégia de investigação capaz de abranger tanto a produção quanto a circulação e o consumo, uma vez que "a tendência predominante do capitalismo é a de reduzir ou anular a diferença entre festas participativas rurais e espetáculos mercantis urbanos" (CANCLINI, op. cit., 131).

O objetivo da investigação em andamento é abordar, no contexto da sociedade global, alguns aspectos do processo de transformação que permeiam a religião e a cultura popular entendendo-as como mudanças de ordem estrutural, que afetam os rituais católicos brasileiros das festas de santos. Buscamos detectar situações em que a comparação entre a observação do presente e a etnografia já publicada nos possibilite enxergar as relações sociais e ideológicas engendradas dentro dos processos de globalização/mundialização, pelos quais o mundo rural no Brasil passou e tem passado a partir da industrialização. 
A proposta é analisar dentro da suposta natureza espetacular os rituais de festas populares em dois estados brasileiros. Em Goiás, os festejos do Divino Espírito Santo e a Semana Santa de Pirenópolis (Brandão, 1974; 1978; 2004; 2009a e 2009b). Em São Paulo, a Festa do Divino Espírito Santo em São Luis do Paraitinga (Brandão, 1981). A transformação da festa religiosa em fenômeno global abrangendo todos os aspectos da vida social revela o papel do econômico, político, religioso e do estético no processo de transformaçãocontinuidade da cultura. Tal fenômeno demonstra que a produção e o consumo do simbólico alcançaram uma nova dimensão na contemporaneidade, uma reconstrução material da ilusão religiosa. A busca por lucratividade e a industrialização do simbólico transformam as festas populares religiosas em entretenimentos e lazer. Frente a essa dinâmica, as identidades populares são reformuladas e reinventadas dentro da sistemática da diversão e da reificação das culturas locais e regionais.

Consideramos que a industrialização acarretou mudanças no cenário das festas, o que nos permite falar em institucionalização do entretenimento-turismo em várias regiões, especialmente no Rio de Janeiro com o carnaval que pode ser considerado como matriz da modernização turística. A partir da década de 20, o Brasil começa a despontar como uma sociedade nacional com foco na "industrialização e cujos deslocamentos simbólicos e materiais definem cada vez mais espaços consagrados ao comércio da diversão" (COUTO, 2012, p. 626). Mais recentemente, o fenômeno da globalização atuou no sentido de situar as culturas populares no processo de desenvolvimento socioeconômico.

A análise do problema da cultura e religião populares em sociedades de origem rural sob o impacto de processos de industrialização e de urbanização deve buscar compreender algumas questões de investigação como: por que, por um lado, sobrevivem e proliferam estes universos considerados míticos, fictícios e fantásticos num mundo que reiteradamente se submete à lógica do mercado e da espetacularização? Quais são os aspectos eficazes destas festas tradicionais, ainda que seu caráter de celebração comunal seja diluído no interior da organizaçao mercantil do lazer turístico? Qual o destino de rituais que perderam seus contextos - ou porque nascem na roça e vêm morrer nas cidades, ou porque perdem o seu lugar na festa onde nasceram - e se empobrecem de gente, de gestos e de significados? Quais os impactos dos meios de comunicação, dos efeitos desagregadores do turismo, da secularização e da mercantilização das cerimônias religiosas no universo das culturas populares? A partir do ritual de origem, quando acontece a espetacularização da festa? 
Outras questões teóricas interessantes se apresentam a partir da visita de um investigador ao local pesquisado por outro: a) como está sendo concebida a mudança nas comunidades tidas como tradicionais; b) qual a ligação entre relações socioeconômicas e concepções culturais pautadas no que se chama de tradição; c) o que é construído como tradicional e como moderno, e de que forma os sujeitos e as instituições expressam ou não essas oposições e as mudanças delas decorrentes.

Essas são questões relevantes que pretendemos responder ao final da pesquisa em desenvolvimento, sempre tendo em mente o espaço das festas populares religiosas. A historiadora Mona Ozouf (1976), em seu clássico estudo sobre a festa popular na Revolução Francesa, chama a atenção para o fato dos eventos festivos apresentarem uma dupla abertura para o passado e para o futuro. De acordo com Ozouf, os sujeitos que as constroem e lhes atribuem significados tendem a reivindicar precedentes sócio-culturais e possibilidades futuras da sua prática, que reproduzam seu conteúdo subjetivo. "Por que festas?", pergunta a autora em questão. "Para compor através delas uma história anual e comemorativa (...), para estabelecer correspondências de um tempo remoto com o tempo presente" (OZOUF, 1976, p. 219). Ainda que as transformações vividas nas festas populares de "caráter tradicional" sejam comumente acompanhadas por uma evocação nostálgica, trata-se de uma intenção restauradora que denota uma espécie de consciência crítica acerca das transformações vividas pelos sujeitos no processo histórico.

\section{Metodologia}

As Ciências Sociais se desenvolvem pela constante renovação teórica, quando dados etnográficos dialogam, contestam ou expandem teorias anteriores. Em decorrência dessa perspectiva, Mariza Peirano (2002) afirma que, autores/obras clássicas são sempre atuais, porque atuam como referência no movimento espiralado mediante o qual o refinamento da disciplina se dá. Tais afirmações vêm ao encontro de nossos anseios, no sentido de mostrar que CRB e suas obras são sempre referências para nós.

Assim sendo, salientamos que o procedimento metodológico utilizado constitui-se de uma análise teórica e empírica de algumas festas religiosas e populares brasileiras, investigadas a partir da etnografia de Carlos Rodrigues Brandão. A pesquisa em andamento contempla as dimensões teórica, documental e uma pesquisa de campo com base na observação participante. 
Privilegiando o espaço das trocas dentro das vivências religiosas dos "catolicismos populares" fortemente marcados pelo sincretismo, esse estudo, embora ainda incipiente, se embrenha no complexo e problemático campo das relações entre a religião e a mudança social. Deste modo, precisa ser proposto de tal forma que o conjunto de investigações a respeito não deixe de considerar pelo menos, algumas das seguintes observações:

- Os efeitos de processos produtores de mudança social como a industrialização, a urbanização, a globalização, a transformação de estruturas de posse e de uso da terra, a redefinição de formas de controle do capital e da apropriação de força de trabalho, bem como a ordem interna de igrejas, a reformulação de suas práticas rituais e da atribuição ideológica de significados que faz por meio de seus agentes eclesiásticos;

- Os efeitos particularizados de contradições que acompanham e provocam mudanças em setores da sociedade sobre as formas de organização do campo religioso, como a ocupação acelerada de espaços urbanos por levas de populações deslocadas do campo; a concentração decorrente de migrantes de baixa renda na periferia dos grandes centros urbanos; o crescimento de domínios de marginalidade tanto urbana quanto rural; as pressões sociais e políticas sobre esferas de participação sociais reservadas à religião e às igrejas;

- Os elementos de fortalecimento e coesão da vida comunitária e da identidade cultural, bem como as políticas de autogestão que concedem às festas condições para não se dissolverem inteiramente num espetáculo e continuarem a oferecer espaços de participação coletiva e transmissão de memória, muito mais do que espaços de atuação de instituições governamentais e turísticas.

Stanley Tambiah (1997, p. 217) sintetiza o potencial do método antropológico ao afirmar que o mesmo "reside em investigar de que maneira forças globais e metropolitanas são retratadas através de formas locais de vida, e como em contrapartida são adaptadas pelas formas locais aos seus próprios propósitos, gerando criativamente seus padrões distintos”. Em sentido similar, questionamos como a partir de uma sociedade globalizada, se remodelam as práticas religiosas vividas por meio de festas e rituais genuinamente populares.

A pesquisa em andamento tem sido empreendida em três dimensões: teórica, documental e pesquisa de campo a partir de observação participante.

\section{Considerações parciais}


Stanley Tambiah (1997), cuja abordagem de ritual já foi comparada ao que LéviStrauss fez com o totemismo e Freud com os sonhos, observa nos fenômenos coletivos e espetáculos de massa uma chave para análise de rituais. A partir de sua obra sobre rituais de violência em cidades como Bombaim, Delhi e Calcutá podemos pensar também sobre a rotinização e a ritualização das festas populares no Brasil e enxergar nas mesmas a dissolução de dicotomias: sagrado/profano, festivo/fervoroso.

A festa pode ser considerada um ritual, um evento coletivo de ruptura da rotina da vida cotidiana, que coloca as pessoas, as instituições e a própria vida social diante de um espelho do que são, quando eles não são a festa. Assim, há uma tendência antropológica remota em considerar o ritual apenas como a solenização cerimonial e formal concentrada em ritos e mitos, tendo quase sempre uma relação com o sagrado, seja ele mágico ou religioso, num sentido mais amplo.

$\mathrm{Na}$ análise de Da Matta, o carnaval e a festa de igreja atuam em confronto. O primeiro opera pela ruptura sendo praticamente um hiato sobre um espaço de trocas sociais contínuas regidas pelos códigos da estrutura, durante o qual há uma separação radical entre o sagrado e o profano (o religioso é expulso/adiado para a quarta-feira de cinzas). Já a festa de santo de igreja, segundo CRB, opera pela "totalização de cosmo ordenado, incorporando elementos profanos e sagrados, solenes e festivos, reunindo dentro da festa elementos do cotidiano que atuam no sentido de integrar e dissolver conflitos”. (BRANDÃO, 1985b, p.199).

Para concluir esta seção ainda com Da Matta, o ritual é frequentemente utilizado para designar momentos solenes da vida social, marcando a passagem do domínio do mundo cotidiano ao mundo dos acontecimentos extraordinários. Nas palavras do autor de Carnavais, malandros e heróis, "a passagem de um domínio a outro é marcada por modificação no comportamento, e tais mudanças criam as condições para que ele seja percebido como especial. Este é o subuniverso das festas e das solenidades”. (DA MATTA, 1983, p. 38)

Diante das acepções, preferimos ampliar o significado do ritual ao afirmar que a conduta festiva não precisa ser necessariamente regida por normas; ao contrário, o que proporciona especificidade aos rituais é a possibilidade da expressão individual alegre e espontânea dos sentimentos. Para além dos significados em torno do universo religioso, as festas rompem com a rotina dos dias comuns, criando um espaço para o entretenimento e o ócio. Essa ruptura com a rotina do trabalho já tinha sido mencionada por CRB num de seus primeiros trabalhos sobre festividades populares, As Cavalhadas de Pirenópolis (1974): 
Há dias, às vezes uma semana, às vezes um pouco mais, em que uma sociedade rural interrompe a sua rotina e se transforma em festa. As pessoas das grandes cidades, acostumadas à experiência do novo e do renovado em sua própria vida urbana e modernizada, dificilmente poderiam compreender a necessidade e a insistência do retorno anual de uma mesma Cavalhada que repete durante três tardes e há mais de cento e cinquenta anos, os mesmo galopes, as mesmas falas e os mesmos resultados (BRANDÃO, 1974, p. 5).

Curioso notar que, passados mais de 40 anos da publicação da referida obra, a Cavalhada de Pirenópolis se encontra num processo de mercantilização da sua tradição, deixando de ser ócio, como observou Brandão, para se tornar negócio.

Um depoimento pessoal do autor ilustra a hipótese inicial deste artigo de que algumas festas tomaram proporções enormes e deixaram de ser rituais originais para se tornarem espetáculos dirigidos às massas: "Era estrada de terra até Pirenópolis quando fui lá fazer pesquisas. Eu dormia dentro do carro e tomava banho no Rio das Almas... Só tinha uma pousada. Hoje em dia, milhares de pessoas e centenas de pousadas"[informação oral]. A percepção aguçada de Brandão vai ao encontro de uma recente pesquisa quantitativa realizada por um grupo da Universidade Estadual de Goiás (UEG) interessado em conhecer o perfil e a demanda de turistas que visitam Pirenópolis. De acordo com os dados coletados, um número expressivo de turistas aponta as Cavalhadas como principal motivação da visita. "Do total de 52 respostas, 20 visitantes disseram que estavam em Pirenópolis para ver a festa" (LÔVO, 2014, p. 125).

Num tour pelos principais sites sobre Pirenópolis, observa-se, notoriamente, o empenho do poder público e dos empreendedores do turismo em transformar os eventos religiosos, como o da Semana Santa, em produtos turísticos a fim de melhorar a oferta do destino. Temos então uma festa de origem rural que, a princípio, foi assimilada pela urbanização e, depois, se espetacularizou a ponto de atrair turistas de todo Brasil, não apenas como espectadores, mas como participantes que ignoram, na maioria das vezes, os significados do ritual. Notamos que o grupo dos mascarados teve seu número de participantes multiplicado a centenas no decorrer das últimas décadas e isso requer uma problematização, considerando que uma festa popular identifica-se com os festeiros e os convidados de uma maneira íntima respaldada na devoção.

Não interessa aqui alongar o debate sobre as sínteses conceituais decorrentes desta concepção de religiosidade popular no Brasil, contudo cabe reiterar que a mesma baseia-se nas formas de devoção do catolicismo colonial brasileiro. Esse, por sua vez, sendo focado no pragmatismo do milagre organiza a vida das pessoas dentro de uma vivência doméstica, ou 
seja, próxima e íntima, acentuando o caráter relacional direto entre homens e santos (HORTA, 2011, p. 79).

O mesmo ocorre em outros universos da chamada cultura popular: uma cantoria, uma procissão, uma congada, um bumba meu boi, uma umbigada, uma folia das almas. Entretanto, ao falarmos de mudança sociocultural na temática das festas populares, considerando a dilemática existente entre modernização da sociedade e a cultura popular, é preciso imprimir novos significados nas relações entre cotidiano, festas e mercado, posto que:

O distanciamento começa quando o turismo (ou a TV, paraíso do viajante de poltrona) toma conta dessas práticas: a festa, exibida, mas não partilhada, toma-se espetáculo. Nesse exato momento, o capitalismo se apropriou do folclore, ocultando o seu teor original de enraizamento (BOSI, 1995, apud FARIAS, 2001, p. 40).

Se por um lado há distanciamento dos significados dos rituais vividos, por outro há uma maior proximidade com valores intrinsecamente mercadológicos. Diante disso, interessa aos objetivos deste trabalho reportar-nos à obra de Edson Farias (2011) que tem como problemática central a relação dilemática entre cultura popular e modernidade, com enfoque no nexo entre economia e cultura, sem perder de vista o cenário político e simbólico em que se engendram esses embates. Superando a visão dualista, Farias está na contramão da tendência habitual de conceber como marginais, no sentido de estarem em margens opostas, essas concepções. No caso específico do Brasil, no que concernem aspectos da cultura popular e folclórica, entre as quais se incluem as festas e folguedos regionais:

[...]têm sido alvo de divulgação em grau formidável, principalmente ao estarem conectadas aos mercados fonográfico, radiofônico e audiovisual, nos quais se dá a consagração de repertórios de música popular, de alguma maneira, vinculada aos nichos regionais do país (axé music, pagode, sertanejo, toadas e forró). Ao mesmo tempo, as conexões entre cultura e economia a partir delas se estendem diante das suas inserções nos roteiros turísticos, como núcleos de divulgação das respectivas regiões a que pertencem. (FARIAS, 2011, p. 86).

Articular o que aqui chamamos de "tradicional" e de "moderno" exige pesquisa de fôlego e leitura minuciosa, mas para o momento vale salientar, a título de conclusão parcial, que neste contexto contemporâneo as festas religiosas das culturas populares estão sendo ressignificadas, mediante uma negociação nova entre as forças do mercado cultural, da globalização e da identidade local.

A concepção de cultura popular como um lugar de resistência e sobrevivência de valores que precisam ser "resgatados" e preservados guarda em si um olhar romântico, nostalgicamente voltado ao passado que, por sua vez, é idealizado e utópico. Considerar os fazeres populares, sejam festas, rezas ou manifestações artísticas, como exemplos de 
alteridade idealizada e autêntica soa como uma interpretação equivocada. É preciso perceber que, dessa articulação conceitual tensa e necessariamente dialética, derivam novos significados: ressignificações culturais diante do processo de globalização.

Pensar manifestações culturais como espaços de produção, reprodução e consumo de bens tangíveis e intangíveis requer uma visão do constante dinamismo das trocas ou hibridizações do campo da cultura, pois novos significados estão sendo a todo tempo dados, sobretudo no contexto contemporâneo em que as culturas populares estão recebendo novos sentidos, num jogo dilemático entre o local e o global, entre a tradição e a modernidade. Deste modo, não se trata de estudar manifestações do nosso patrimônio cultural imaterial de forma essencializada, fora dos contextos globais e com os rótulos da "deturpação" e "descaracterização" de tais fenômenos; mas sim, de pensá-las como lugar de adaptações, sínteses, ressignificações e encontros culturais. Coaduna-se com essas reflexões Peter Burke quando ressalta que "a identidade cultural é frequentemente definida por contraste" (BURKE, 2003, p. 81).

\section{Referências}

BRANDÃO, Carlos Rodrigues. Cavalhadas de Pirenópolis. Goiânia: Oriente, 1974.

. O Divino, O Santo e a Senhora. Rio de Janeiro: MinC, FUNART, 1978. . Sacerdotes de Viola. Petrópolis: Vozes, 1981.

. Memória do Sagrado: estudos de religião e ritual. São Paulo: Ed. Paulinas, 1985b. . De tão longe eu venho vindo. Goiânia: Editora UFG, 2004.

. O saber, o cantar e o viver do povo. São José dos Campos/SP: Coleção Cadernos de Folclore, 2009a.

. A Clara Cor da Noite Escura. Uberlândia: EDUFU; Goiânia: Editora da Universidade Católica de Goiás, 2009b.

BURKE, Peter. Hibridismo Cultural. São Leopoldo. RS. Editora Unisinos, 2003.

CANCLINI, Nestor Garcia. As Culturas Populares no Capitalismo. São Paulo: Ed. Brasiliense, 1983.

COUTO, Bruno Gontyjo do. Ócio e negócio: festas populares e entretenimento-turismo no Brasil. Caderno CRH, v. 25, n. 66, p. 625-627, 2012.

DA MATTA, Roberto. Carnavais, Malandros e Heróis. Para uma Sociologia do dilema brasileiro. $4^{\text {a }}$ edição. Rio de Janeiro: Zahar, 1983. 
FARIAS, Edson Silva de. Ócio e negócio: festas populares e entretenimento-turismo no Brasil. Curitiba: Editora Appris, 2011.

HORTA, Ana P. S. Os Reis da Canastra: os sentidos da devoção nas folias. Dissertação de Mestrado em História Social. USP, São Paulo: 2011.

KELLNER, Douglas. A cultura da mídia e o triunfo do espetáculo. Líbero, v. 6, n. 11, 2007.

LÔBO, Tereza Caroline et al. Perfil do turista que frequenta Pirenópolis/Goiás. Revista Plurais-Virtual (ISSN 2238-3751), v. 4, n. 2, p. 117-133, 2015.

MESQUITA, Claudia Cardoso. Deus está no particular. Representações da experiência religiosa em dois documentários brasileiros contemporâneos. São Paulo: USP, 2006. Tese Programa de Pós-Graduação da USP em 2006.

OZOUF, Mona. A festa sob a Revolução Francesa. História: novos objetos. Rio de Janeiro: Francisco Alves, p. 217-231, 1976.

ORTIZ, Renato. Mundialização e cultura. São Paulo: Brasiliense, 2007.

PEIRANO, Mariza. (org.). O Dito e o Feito. Rio de Janeiro: Relume Dumará: Núcleo de Antropologia da Política/UFRJ, 2002.

TAMBIAH, Stanley J. Continuidade, integração e horizontes em expansão. Mana, v. 3, n. 2, p. 199-219, 1997. 